DOI 10.37882/2223-2982.2020.12-3.25

\title{
КОГНИТИВНЫЙ И ЛИНГВОДИДАКТИЧЕСКИЙ АСПЕКТЫ СТРУКТУРНО-СЕМАНТИЧЕСКОГО АНАЛИЗА РЕАЛИЙ
}

\section{COGNITIVE AND LINGUODIDACTIC ASPECTS OF STRUCTURAL AND SEMANTIC ANALYSIS OF CULTURE-SPECIFIC ELEMENTS \\ L. Chistyakova}

Summary: Within the framework of the cognitive approach, culturespecific element are considered as representatives of culture, which play a crucial role in shaping the language picture of the world. Russian realities and their German correspondences, identifying common and different semantic components will help to draw a conclusion about the similarities and differences in the German and Russian language pictures of the world.

Keywords: culture-specific element, language picture of the world, structural and semantic analysis, semantic component.

\author{
Чистякова Людмила Александровна \\ К.филол.н., доцент, Елецкий Государственный \\ Университет им. И.А. Бунина \\ luchis@mail.ru
}

Аннотация: В рамках когнитивного подхода реалии рассматриваются как репрезентанты культуры, играющие важнейшую роль в формировании языковой картины мира. Компонентный анализ русских реалий и их немецких соответствий, выявление общих и различных семантических компонентов поможет сделать вывод о сходствах и различиях в немецкой и русской языковых картинах мира.

Ключевые слова: лингвострановедческая реалия, языковая картина мира, структурно-семантический анализ, семантический компонент.

Н.Л. Новиковой (2003). А.А. Кретов и Н.А. Фененко разработали лингвистическую теорию реалии (2013).

В рамках новой научной парадигмы реалии, хранящие информацию о культурном коде нации, рассматриваются как репрезентанты культуры. Реалии как носители колорита, зримые языковые элементы национального своеобразия рассматриваются в трудах Й. Вайсгербера (многократно цитируемый в современных исследованиях «Родной язык и формирование духа»), М.Л. Вайсбурд, Вл. Россельса. Исследование когнитивной функции языка относится к актуальным направлениям современной лингвистики. Языковая картина мира преобразует восприятие мира и накладывает отпечаток на то, как человек видит себя и окружающую среду. Учитывая национально специфический характер реалий, можно предположить исключительно важную роль этой категории лексики в формировании национальной языковой картины мира.

Отмечая множество подходов и дефиниций этого термина, сошлемся на определение Вагановой: «Языковая картина мира - это исторически сложившаяся в обыденном сознании данного языкового коллектива и отраженная в языке совокупность представлений о мире, определенный способ концептуализации действительности» [1:22]. По мнению исследовательницы, «языковая картина мира как единый «живой организм» четко структурирована и в языковом выражении является многоуровневой» [там же]. Она определяет: 
1. особый набор звуков и звуковых сочетаний;

2. особенности строения артикуляционного аппарата носителей языка;

3. просодические характеристики речи;

4. словарный состав;

5. словообразовательные возможности языка;

6. синтаксис словосочетаний и предложений;

7. паремиологический багаж. [1]

Языковая картина мира обусловливает суммарное коммуникативное поведение, понимание внешнего мира природы и внутреннего мира человека и языковую систему. [1] Согласно приведенной схеме, реалии наряду с другими словами в системе вокабуляра относятся к «единицам четвертого уровня», но по своей значимости занимают первые позиции. «Из всех уровней языковой структуры наиболее тесная и яркая связь языка и национальной культуры проявляется в области лексики и фразеологии», - справедливо замечает Д.Г. Мальцева [9:22].

Различие языков на уровне слова состоит в том, что слова, обозначающие в разных языках одни и те же предметы, могут иметь разную внутреннюю форму. Проиллюстрируем это на достаточно простом примере. В начале весны, в канун Великого поста и в Германии, и в России проходят традиционные многодневные празднования, обозначаемые в русском языке словом «масленица», а в немецком «Karneval» или «Fasching. Наличие фоновых знаний или обращение к лингвострановедческим справочникам позволяют выделить основные компоненты значения слов.

В значении русского слова «масленица» можно выделить следующие семы:

1. Языческое происхождение (встреча весны, начало полевых работ).

2. Связь с главным христианским праздником Пасхи.

3. Длительность в одну неделю.

4. Отдельная тематика для каждого дня (понедельник - «встреча», вторник - «заигрыш», среда «лакомства», четверг - «широкая масленица», пятница - «к теще на блины», суббота - «проводы», воскресенье - «Прощеный день»)

5. Массовые народные гуляния.

6. Сожжение соломенной куклы Масленицы.

7. Ежедневное выпекание блинов.

В значении немецкого «Karneval»:

1. Связь с языческим ритуалом изгнания зимы.

2. Длительность - с 11 ноября до Великого поста, установленного христианской церковью.

3. Установленнаяпоследовательность основныхсобытий:торжественное открытие (StichtagdesKarnevals), праздник Трех Королей (Drekönigfest), заседания карнавальных обществ (Karnevalsitzung), карнавальные шествия, заключительная праздничная неделя, Розовый понедельник (Rosenmontag), Пепельная среда (Achermittwoch), в сельской местности - сожжение чучела Зимы.

4. Массовые гуляния

5. Региональные особенности (AachenerKarneval, KölnerKarneval, DüsseldorferKarneval, MünchenerFaschung, schwäbisch-alemannischeFasnet).

В результате сравнение можно установить наличие следующих общих семантических компонентов в словах «масленица» и «карнавал»:

1. Праздничное событие.

2. Многодневный праздник.

3. Массовые гуляния.

4. Языческое происхождение.

5. Предшествование Великому посту в настоящее время.

Различие в значениях представлены меньшим количеством сем: непременное сожжение чучела Масленицы (в Германии - преимущественно в сельской местности) и обязательное приготовление блинов - входят в семантическую структуру русского слова «масленица», значительные региональные различия (вплоть до названия - Karneval, Fasching, Fasnet) и известная соревновательность (кельнский и дюссельдорфский карнавалы) - дополняют значение немецкой лексемы «Karneval“.

Анализ сходных компонентов приводит к сравнению процесса перехода от языческих традиций к христианским на историческом уровне, констатации неизменной потребности человека в шумных праздниках перед длительной работой или постом с точки зрения психологии и так далее. Различия в семантической структуре позволят оценить важность единства или подчеркнутого своеобразия (обособленности) традиций, обрядов, сознания в пределах целого народа или отдельных регионов страны, отношение к угощению и тому подобное.

Сравнение по структурно-семантическому признаку русских и немецких реалий с применением методов компонентного и контекстуального анализа, выявление общих и различных семантических компонентов позволят выделить реалии, содержащие в семантической структуре наибольшее количество мультикультурных (общекультурных) компонентов и составить перечень концептуально значимых реалий на русском и немецком языках. Их сравнительно-исторический, статистический анализ поможет сделать вывод о сходствах и различиях в немецкой и русской языковых картинах мира.

Исследование таких качественных различий на языковом материале реалий может стать предметом анализа и в процессе преподавания иностранного языка. С точки зрения лингводидактики, такая работа на занятиях по иностранному языку представляется творческим, 
продуктивным процессом освоения своего и чужого культурного пространства и формирования вторичной языковой личности в результате обогащения картины мира, сформированной родным языком, иноязычными концептами. Преподавание иностранного языка имеет в наше время прочное методологическое обоснование в современных лингвистических теориях о связи языка и мышления, языка и культуры. Впервые высказанная немецким ученым конца 18 - начала 19 века В. Гумбольдтом идея о тождественности языка и духа народа получила развитие и в европейской, и в отечественной науке. „Отец современной философии языка» [12:97] говорил и роли иностранного языка: «Каждый язык описывает вокруг народа, которому принадлежит, круг, откуда человеку дано выйти лишь постольку, поскольку он тут же вступает в круг другого языка. Освоение иностранного языка можно было бы уподобить завоеванию новой позиции в прежнем видении мира» (Гумбольдт; цит. по [13:131]. Л. Вайсгербер рассматривает язык как фактор формирования мышления, считая, что «из общего владения языков члены одного языкового сообщества черпают значительную однородность основ мышления и форм выражения». [2:105] . В введении к истории немецкого языка В.М. Жирмунский говорит: «Каждый язык должен изучаться в тесной связи с историей народа, который был и является создателем и носителем данного языка». [6:13] Способность языка фиксировать и сохранять информацию о реальности, постигаемой человеком и той общностью людей, к которой индивид принадлежит, отмечают в исследованиях Е.М. Верещагин и В.Г. Костомаров [3]. «Средством проникновения в инородную культуру со всеми ее национально-этническими и социально-классовыми особенностями» называет язык Д.Г. Мальцева [9:21].

Таким образом, применение сравнительного подхода к изучению реалий в аспекте структурно-семантического анализа будет способствовать, с точки зрения когнитивного лингвистического подхода, выявлению их роли в формировании языковой картины мира и воспитанию вторичной языковой личности в лингводидактическом рассмотрении.

\section{ЛИТЕРАТУРА}

1. Е.Г. Ваганова. Языковая картина мира: онтологический анализ // Филологические науки: Наука о человеке: гуманитарные науки. Омск. 2015. №1(19). C.20-29.

2. Вайсгербер Й.Л. Родной язык и формирование духа / пер. с нем.; вступ. ст. и коммент. О.А. Радченко. Серия «История лингвофилософской мысли».. Изд. 2-е, испр. и доп. - М.: Едиториал УРСС, 2004. - 232 с.

3. Верещагин Е.М., Костомаров В.Г. Язык и культура: лингвострановедение в преподавании русского языка как иностранного: методическое руководство. M.,1990. $-246 c$.

4. Влахов С.И., Флорин С.П. Непереводимое в переводе. - Изд. 4-е- М.: «Р.Валент», 2009. 360 с.

5. Вторушина Ю.Л. Формирование межкультурной компетенции в контексте профессиональной подготовки будущих учителей иностранного языка: на материале преподавания английского языка с использованием народного фольклора: Дис. ... канд. пед. наук: 13.00. Московск. пед. гос. ун-т. - М. [б.и.], 2007.218c.

6. Жирмунский В.М. История немецкого языка. М.: Изд-во литературы на иностранных языках, 1948. 300с.

7. Кретов А.А. Лингвистическая теория реалии // Вестник ВГУ. Серия: лингвистика и межкультурная коммуникация. 2013. № 1. С.7-13.

8. Лиликович 0.С. Реалии в отечественной и зарубежной лингвистической традиции // Вестик ВГУ. Серия: лингвистика и межкультурная коммуникация. 2015. № 4. С. 101-104.

9. Мальцева Д.Г. Лингвострановедческий аспект в процессе изучения и преподавания немецкого языка // Ярославский педагогический вестник. 2000. №1(23). С. 21-27.

10. Мосиенко Л.В. Лингвокультурологическая проблема классификации реалий // Вестник ОГУ. 2005. № 11. С. 155-161.

11. Оленев С.В. Изучение родного языка как формирование языковой личности // Социогуманитарный вестник. 2010. №4. С. 84-90.

12. Радченко 0.А. Лингвофилософские опыты В. фон Гумбольдта и постгумбольдтианство // Вопросы язык0знания.2001.№3. С. 96-25.

13. Селеменева 0.А. Формирование концепции языковой картины мира в работах отечественных и зарубежных лингвистов конца XVIII - начала XX века // Филологические науки. Вопросы теории и практики. 2012. № 1(12). С. 130-134.

(c) Чистякова Людмила Александровна (luchis@mail.ru). 